\title{
Ambientalização curricular no ensino superior: formação e sustentabilidade nos cursos de graduação
}

Curricular environmentalization in higher education: training and sustainability in graduation courses

\author{
Volumen 17, Número 2 \\ Mayo-Agosto \\ pp. $1-20$
}

Este número se publica el $1^{\circ}$ de mayo de 2017

DOI: http://dx.doi.org/10.15517/aie.v17i2.28676

\author{
Mariza Rotta \\ Airton Carlos Batistela \\ Sergio Ricardo Ferreira
}

Revista indizada en REDALYC, $\underline{\text { SCIELO }}$

Revista distribuida en las bases de datos:

\section{LATINDEX, DOAJ, REDIB, IRESIE, CLASE, DIALNET, SHERPA/ROMEO, QUALIS-CAPES, MIAR}

Revista registrada en los directorios:

ULRICH'S $, \underline{R E D I E}, \underline{R I N A C E}, \underline{\text { OEI }}, \underline{\text { MAESTROTECA }}, \underline{\text { PREAL, }}$ 


\title{
Ambientalização curricular no ensino superior: formação e sustentabilidade nos cursos de graduação
}

Curricular environmentalization in higher education: training and sustainability in graduation courses

\author{
Mariza Rotta ${ }^{1}$ \\ Airton Carlos Batistela ${ }^{2}$ \\ Sergio Ricardo Ferreira ${ }^{3}$
}

\begin{abstract}
Resumo: Este ensaio apresenta a proposta de articulação curricular de cursos de graduação de licenciatura, bacharelado e tecnólogo por meio das disciplinas que congregam o eixo - ambientalização dos espaços educativos sustentáveis - como forma de apresentar a proposição de uma formação acadêmica voltada ao desenvolvimento sustentável e à educação ambiental dentro e fora da universidade. A linha de formação está explanada de forma que alinhave ensino e investigação propiciando práticas e desenvolvimento de conhecimentos a partir dos elementos que integram o tema meio ambiente e sustentabilidade nas atividades acadêmicas e de gestão institucional. O contexto base da discussão se dá a partir da construção do desenho curricular com disciplinas de cunho interdisciplinar que integrará a práxis pedagógica da Faculdade Municipal de Educação e Meio Ambiente FAMA da região Sul do Brasil. Buscando romper com currículos disciplinares tradicionais que apresentam maiores limitações ao tratar de questões centrais de formação que requer olhar integrado e compreensão da complexidade das questões ambientais. Este ensaio se inicia expondo a problemática ambiental a partir da estruturação do pensamento moderno para, em seguida, abordar o assunto nos dias atuais e, por fim, expor a proposta institucional sobre esta questão.
\end{abstract}

Palavras - chave: ambientalização curricular; educação ambiental; ensino superior, Brasil.

Abstract: This essay presents the proposed curriculum articulation of graduation, bachelor's and technologist undergraduate courses through the disciplines that bring the axis - environmentalization of sustainable educational spaces - as a way to present the proposition of an academic training focused on sustainable development and environmental education within and outside university. The training line allows the articulation of teaching and research that promotes practice and development of knowledge from the elements that integrate the environment topic and sustainability in academic and institutional management activities. The basic context of the discussion takes place from the construction of curriculum design with interdisciplinary nature of disciplines that integrate the pedagogical praxis of Education and Environment's Municipal School - FAMA of Southern Brazil. This seeks to break with traditional disciplinary curricula that presents greater limitations when dealing with core issues of training that requires integrated look and understanding of the complexity of environmental issues. This essay starts exposing environmental problems from the structure of modern thought, to then briefly address the issue in the present day and finally expose the institutional proposal on this question.

Key Words: curricular environmentalization; environmental education; higher education, Brazil.

\footnotetext{
${ }_{1}^{1}$ Professora Assistente da Faculdade Municipal de Educação e Meio Ambiente FAMA, Brasil. Doutoranda em Educação, Mestre em Ciência Jurídica. Correio eletrônico:mzrotta@gmail.com

2 Professor Assistente da Faculdade Municipal de Educação e Meio Ambiente FAMA, Brasil. Doutor em Educação. Correio eletrônico: batistela.airton@gmail.com

${ }^{3}$ Professor Assistente da Faculdade Municipal de Educação e Meio Ambiente FAMA, Brasil. Mestre em Educação. Correio eletrônico:
} sergioferreira1966@gmail.com

Ensayo recibido: 30 de junio, 2016

Enviado a corrección: 6 de febrero, 2017

Aprobado: 13 de febrero, 2017 
Resumen: Este ensayo presenta la propuesta de articulación curricular de cursos de graduación de licenciatura y tecnología por medio de las asignaturas que congregan el eje - ambientación de los espacios educativos sustentables como forma de presentar la proposición de una formación académica volcada al desarrollo sustentable y a la educación ambiental dentro y fuera de la universidad. La línea de formación está expuesta de forma que articula la enseñanza e investigación propiciando prácticas y desarrollo de conocimientos a partir de los elementos que integran el tema medio ambiente y sostenibilidad en las actividades académicas y de gestión institucional. El contexto base de la discusión se da a partir de la construcción del diseño curricular con asignaturas de cuño interdisciplinario que integrará la praxis pedagógica de la Facultad Municipal de Educación y Medio Ambiente FAMA de la región Sur de Brasil. Este busca romper con currículos disciplinares tradicionales que presentan mayores limitaciones al tratar de cuestiones centrales de formación que requiere una mirada integrada $y$ comprensión de la complejidad de las cuestiones ambientales. Este ensayo se inicia exponiendo la problemática ambiental a partir de la estructuración del pensamiento moderno para, después, abordar el asunto en la actualidad $y$, por fin, exponer la propuesta institucional sobre este tema.

Palabras clave: ambientación curricular; educación ambiental; enseñanza superior, Brasil.

\section{Introdução}

Nesta época a temática meio ambiente e as dimensões que a compreendem a partir do elemento sustentabilidade revestem-se de particular importância ao compor a estrutura curricular de cursos de graduação de ensino superior, abrindo a possibilidade de desenvolver uma cultura universitária que sugira e introduza mudanças no que se refere a metodologias e abordagens para ambientalizar o espaço educativo universitário, favorecendo a articulação com a pesquisa, extensão e ensino em caráter interdisciplinar.

Nessa ótica educar a partir das questões ambientais implica em esforço com foco no discernimento de modelos interpretativos em relação a questões sociais e ambientais e, por outro, acessar experiências inovadoras e práticas com características alternativas. Nessa linha surge a concepção da universidade como um dos "espaços educadores sustentáveis" que são aqueles que "tem a intencionalidade pedagógica de se constituir em referências concretas de sustentabilidade socioambiental" (Trajber e Sato, 2010, p. 71).

Tendo em vista a forte vinculação do meio ambiente com a práxis pedagógica organizada por essa Instituição de Ensino Superior a abordagem ambiental será contemplada nos Projetos Políticos Pedagógicos dos Cursos - PPCs por meio de disciplinas que perpassam o currículo com o mesmo eixo (meio ambiente e sustentabilidade) em cursos distintos de formação e unificados por um tema. Assim, o futuro profissional estará apto não apenas a conhecer, aplicar e desenvolver tecnologias, mas também a avaliar seus impactos sobre o meio ambiente, e, para que tais objetivos não sejam apenas retóricos, as disciplinas devem ser contempladas não só nas ementas, mas com uma equipe de professores que desenvolverá a proposta de formação que trabalhará coletivamente de forma a articular a integração dos conhecimentos respeitando as diversas áreas de conhecimento acadêmico que compõem a 
turma, elucidando conceitos sobre o tema que no decorrer do tempo constituem a base das discussões enunciadas por autores como Leff (2000), Moraes (2004), Leite Lopes (2006), Morin e Kern (1993), Jacobi e Luzzi (2004).

Neste percurso a discussão sobre a temática ambiental não se limitará a uma única disciplina voltada para a apresentação de princípios e conceitos básicos relacionados a meio ambiente, mas permeará a matriz curricular de forma interdisciplinar por meio do eixo ambientalização dos espaços educativos sustentáveis - dessa forma haverá um mínimo de certeza de que os programas de curso elaborados pelos docentes titulares das disciplinas atentem para um pensamento ambiental sistêmico que permite uma melhor compreensão das diferentes flechas do conhecimento caracterizada pela interdisciplinaridade como nos ensina Basarab Nicolescu (2000).

Essa proposição comina com a necessidade de saber ultrapassar os limites de uma disciplina e conservar o que for importante e necessário, destacando assim a natureza disciplinar que deve ser, ao mesmo tempo, aberta e fechada. Aberta às inovações, ao inesperado e ao novo, aberta a novas metodologias e estratégias, mas relativamente fechadas em relação às finalidades e objetivos educacionais que estes deverão ser revisados sempre que necessário.

Desta forma pactua-se com Leite Lopes (2006) que ao definir ambientalização a concebe como a abertura das diversas esferas sociais para a questão ambiental. Com a tentativa de inserir a questão ambiental no campo educacional percebe-se o surgimento de uma tendência nos debates sobre educação que é a de ambientalizar os currículos, dando origem assim ao termo conhecido como ambientalização curricular, que se traduz pela possibilidade da apropriação das diversas dimensões do ambiente pela organização curricular nos cursos de ensino superior.

\section{Ambientalização dos espaços curriculares}

O termo ambientalização aqui proposto refere-se à criação de um ambiente nos currículos de variados cursos e, na prática, um trabalho pedagógico desenvolvido coletivamente, promovendo a integração de centenas de acadêmicos de cursos distintos com disciplinas comuns do núcleo de ambientalização dos espaços. Leite Lopes (2006) define ambientalização como um neologismo semelhante a alguns outros usados nas ciências sociais para designar novos fenômenos ou novas percepções de fenômenos vistos da perspectiva de um processo. Acrescenta que a ambientalização reporta-se como interiorização das diferentes 
facetas da questão pública do meio ambiente, neste caso em questão, com a criação de disciplinas neste núcleo vinculadas ao meio ambiente e inseridas nos projetos pedagógicos dos cursos de graduação em funcionamento na instituição. Alerta, ainda, o autor, que o "processo histórico de ambientalização, assim como outros processos similares, implica simultaneamente transformações no Estado e no comportamento das pessoas (no trabalho, na vida cotidiana, no lazer)". Exatamente por essa indicação que pretendemos explanar o processo de ambientalização dos espaços escolares.

A Faculdade Municipal de Educação e Meio Ambiente - FAMA, seguindo as orientações emanadas da Política Estadual de Educação Ambiental do Estado do Paraná - Brasil embasada na Deliberação nº 04/2013, de 12 de novembro de 2013, do Conselho Estadual de Educação que estabelece Normas estaduais para a Educação Ambiental no Sistema Estadual de Ensino do Paraná, com fundamento na Lei Federal no 9.795/1999, Lei Estadual no 17.505/2013 e Resolução CNE/CP nº 02/2012, e ainda, na Deliberação nº 02/2015 CEE/PR que dispõe sobre as Normas Estaduais para a Educação em Direitos Humanos no Sistema Estadual de Ensino do Paraná, procedeu à reestruturação de seus Projetos Políticos Pedagógicos - PPCs constituindo como Eixo Central de cada curso de graduação a Ambientalização dos espaços educativos sustentáveis.

Há, em nível mundial, um intenso movimento pela ambientalização dos cursos, currículos e espaços universitários. Esta preocupação destaca a responsabilidade ambiental das Instituições de Ensino Superior - IES, à luz da sustentabilidade, em todas as atividades acadêmicas e administrativas.

Neste contexto podemos entender a ambientalização referindo-se à necessidade do tratamento dado às questões ambientais, pelas diferentes disciplinas dos cursos de graduação, com vistas a subsidiar movimentos de ambientalização curricular e de implantação de processos formativos que contemplem a Educação Ambiental - EA, no âmbito das Instituições de Ensino. Refere-se então a uma reflexão crítica que problematiza a realidade com vistas à resolução ou minimização de tais problemas.

Neste sentido, cabe ressaltar que a ambientalização curricular envolve um processo complexo de formação de profissionais que se comprometam com o estabelecimento das melhores relações possíveis entre sociedade e natureza, assim como práticas e políticas acadêmicas de ensino, pesquisa e extensão. Desta forma o Ensino Superior deve se tornar um espaço educativo sustentável, proporcionando aos estudantes vivência de princípios, atitudes e valores da sustentabilidade. Para Morin e Kern (1993) o currículo prescinde de uma 
relação objetiva, com foco na discussão e para a compreensão do espaço unindo teoria e prática e, para isso "recolocá-los em seu meio ambiente para melhor conhecê-los, sabendo que todo ser vivo só pode ser conhecido na sua relação com o meio que o cerca, onde vai buscar energia e organização". O que se constata, na maioria das vezes, é a existência de currículos que primam por ensinar história, geografia, química e física dentro de,

(...) categorias isoladas, sem saber, ao mesmo tempo, que a história sempre se situa dentro de espaços geográficos e que cada paisagem geográfica é fruto de uma história terrestre; sem saber que a química e a microfísica têm o mesmo objeto, porém, em escalas diferentes. (Morin e Kern, 1993, pp. 1-2)

O mundo contemporâneo tem sido marcado, dentre outros aspectos, pelo desenvolvimento da ciência e da técnica e por importantes mudanças geopolíticas e culturais. Em decorrência, demandas sociais e ambientais têm sido sucessivamente preteridas em favor de preceitos econômicos e políticos que têm gerado uma sociedade na qual, cada vez mais, os benefícios propiciados pelos avanços técnico-científicos estão ao alcance de poucos, enquanto os custos desse processo são socializados a todos. A crise socioambiental instalada nesse contexto encontra-se em momento de grande discussão entre os envolvidos.

Entendemos que o campo da educação ambiental vem se apresentando como um campo profícuo de discussões em torno desta crise. Ao lado disso é preciso acrescentar que a educação ambiental não se dá sem a presença de políticas e propostas de gestão da educação e do meio ambiente. Isto abarca, necessariamente, uma reflexão sobre os conhecimentos veiculados sobre meio ambiente, na imperiosa necessidade de repensar valores e atitudes individuais e coletivos e na participação política, voltada para ações em favor do ambiente. Para Jacobi (2005) a preocupação em estabelecer uma prática de ensino e pesquisa a partir de uma

[...] perspectiva interdisciplinar enfatiza a importância dos processos sociais que determinam as formas de apropriação da natureza e suas transformações, por meio da participação social na gestão dos recursos ambientais, levando em conta a dimensão evolutiva no sentido mais amplo e incluindo as conexões entre as diversidades biológica e cultural, assim como as práticas dos diversos atores sociais e o impacto da sua relação com o meio ambiente. (p. 246) 
Embora esta proposta seja ainda iniciante, a Educação Ambiental, entendida na sua globalidade, vem encontrando expressivo espaço no Brasil seja em projetos de ação, em pesquisas, na organização dos educadores e na aprovação de legislação. Também há de se considerar a importância que assumem os debates e a emergência de diferentes abordagens teóricas que se contrapõem, na medida em que assim como se constroem argumentos pautados pelo conceito de Desenvolvimento Sustentável e suas possibilidades, emergem criticas a estas abordagens, porque não propõem questionamentos estruturais em relação ao modelo existente. Muitos encontros têm sido realizados em nível nacional e internacional e nestes espaços se criam oportunidades para a multiplicação de ideias e de posicionamentos, assim como de ações concretas nos espaços acadêmicos e a possibilidade da temática ser inserida nas atividades curriculares.

A problemática deste contexto vem de longe, desde a passagem da idade média à idade moderna, estabelecendo uma caminhada de profundas mudanças, porque não dizer, de essenciais mudanças no campo socioambiental, tão determinantes, que caracterizaram toda posteridade, seja no campo político, econômico ou científico. Nesse contexto Jacobi (2005) diz que a relação entre o meio ambiente e educação assume um papel cada vez mais desafiador, demandando a emergência de novos saberes para apreender processos sociais cada vez mais complexos e riscos ambientais que se intensificam. Acrescenta ainda, o autor, que nas suas múltiplas possibilidades, abre um estimulante espaço para um repensar de práticas sociais e o papel dos educadores na formação de um sujeito ecológico ${ }^{4}$.

A confluência de forças econômicas e políticas, na estruturação de um novo modo de produção, estabeleceram, com precisão, a necessidade de construção de um novo modo de pensar e agir, que, em pouco tempo, possibilitou o pleno estabelecimento de um definitivo modelo de sociedade que perdura até hoje. É exatamente sobre a construção deste novo modelo de pensamento, que vai se fundamentar em um novo modelo econômico e político.

Parcela significativa do debate contemporâneo na área da ciência tangencia, de alguma maneira, o tema da modernidade e da herança iluminista e, não raramente, respostas são dadas em uma perspectiva da modernidade.

\footnotetext{
4 Para Carvalho (2004) "sujeito ecológico" é um tipo de subjetividade orientada por sensibilidades solidárias com o meio social e ambiental, modelo para a formação de indivíduos e grupos sociais capazes de identificar, problematizar e agir em relação às questões socioambientais, tendo como horizonte uma ética preocupada com a justiça ambiental.
} 
O termo moderno ${ }^{5}$ é de difícil precisão. Vamos optar por tratá-lo como sendo composto por uma diretriz central fundamentada em torno da postura relacional homem/natureza, mesmo que constituído por uma vasta gama de tendências intelectuais e políticas que surgiram aí, a partir das experiências vividas pela intelectualidade.

O eixo central desta discussão é então um fio condutor que norteia o pensamento moderno fundamentado na possibilidade de objetivação do mundo, onde, a natureza transforma-se na fonte única, para a técnica, a ciência e a indústria.

O entendimento da modernidade, especialmente pela perspectiva do padrão relacional sociedade/natureza, depende, fundamentalmente, da compreensão da instauração de algumas ideias chave, a partir das quais se edifica o construto ideacional moderno, que serve como cosmovisão norteadora do desenvolvimento das sociedades humanas a partir do século XVII. É no bojo desta perspectiva que se pode compreender o sentido da crise socioambiental atual como intensificação gradativa dum processo que se assenta, por um lado, num padrão compreensivo da realidade (científico, filosófico, ético) e por outro, num padrão intervencionista (desenvolvimentista, tecnológico) sobre essa mesma realidade.

$\mathrm{Na}$ história das ideias, este caminho significou fundamentalmente uma recolocação do ser humano no centro da realidade e, principalmente, na base das determinações do desenvolvimento histórico das sociedades. Isto representa um processo de desvelamento da natureza humana, no sentido da percepção do potencial fundamental humano: a capacidade de compreensão da realidade. Ao dar-se conta da necessidade de conhecer o que perpassa a natureza humana, o homem parte (novamente) na busca do conhecimento, o que traz, como consequência, uma reinserção no centro das diretrizes de sua evolução histórica, a partir do assombroso desenvolvimento cognitivo que empreende.

A modernidade se instaura, portanto, sobre o desvelamento dessa indeterminação existencial no humano; quer dizer, sobre a perspectiva de que nada parece prescrever, deterministicamente, nosso devir histórico. Não precisamos estar, então, necessariamente, atrelados à dinâmica natural; podemos transbordá-la, subvertê-la, subjugá-la: eis o ideário liberal da modernidade, vivenciado pelo liberalismo, que rompeu com a visão da providência divina, dando ao homem um caráter histórico e livre.

\footnotetext{
5 Não são poucos os autores (Harvey, 1999; Lyotard, 1998; Alvesson e Deetz, 1998; Reed, 1998; Demo, 1997; Featherstone, 1996; Kilduff e Mehra, 1997; Huyssen, 1991), que tratam do conceito de Moderno, Modernidade e Pós-modernidade.
} 
A visão mecanicista (racionalista) de mundo, nascidas a partir de Descartes, Bacon e Galileu e a prática científica tradicional que consolida o antropocentrismo, empreende, a partir do século XVII, um processo gradativo de separação humana da dinâmica natural do mundo. Dinamiza-se a partir daí uma nova visão de meio natural essencialmente utilitarista. Cientificamente, consolida-se então, a concepção da ciência manipulação que, aliada à emergência do fenômeno tecnológico moderno, define uma condição humana de estar sobre o mundo e com o mundo ao dispor da ação conhecedora e transformadora humana. Socialmente, desenvolve-se uma sociedade crescentemente energívora e imbuída de valores individualistas e materialistas.

O mecanicismo invade, decisivamente, nossa estrutura perceptiva da realidade e todo universo passa a ser percebido mecanicamente. Newton consolida essa concepção com a construção das bases da Física Moderna Clássica, assentada na alegoria do universo máquina, um gigantesco mecanismo de relógio. Essa contribuição teórica de Newton foi significativa para a cosmovisão moderna, pois ao encadear a concepção mecânica do universo acaba ordenando, também, o pensamento e a percepção do meio natural, que vigora até os estertores do modelo civilizacional moderno, agora, mecânico.

Instaura-se uma tendência de secularização da natureza, tendo por base a dualidade espírito matéria ditada por Descartes. Torna-se evidente o predomínio do determinismo no processo analítico da natureza, cujas consequências podem ser medidas num amplo espectro de conhecimentos científicos da natureza. Todo o desenvolvimento da agricultura moderna, por exemplo, com o intenso processo de artificialização da dinâmica natural produtiva e o rol de receitas fragmentadas e determinísticas para a produção, bem como a revolução tecnológica no campo obedecem a esse princípio.

Dessa cosmovisão mecanicista deriva uma tendência de geração de procedimentos produtivos tendencialmente mecanizados, determinísticos e pesados. Ademais, é a industrialização que se inscreve no âmago desse processo, ou seja, industrializar significa, irreversível e cabalmente, fragmentar unidades vitais no sentido da artificialização.

Com o desenvolvimento do arcabouço científico filosófico moderno temos a definição do padrão relacional sociedade/natureza que se intensifica ao longo de quatro séculos seguintes. Nas formas de interferência que se estabelecem entre o desenvolvimento das sociedades humanas e a dinâmica natural dos ecossistemas, encontramos essa perspectiva norteadora básica: a ideia de (possível) separação entre os domínios social e natural, e a perspectiva de dominação do primeiro sobre o segundo e de crescente interferência do social sobre o natural. 
A conformação mais geral da modernidade assenta-se sobre esse princípio compreensivo e vemos, claramente, que todos os problemas sistêmicos que vivenciamos derivam, diretamente, da intensificação desse processo. É nesse sentido que vários autores atestam a crise da modernidade como originada no padrão relacional equivocado sociedade/natureza.

É importante observar que de toda essa perspectiva origina-se um ethos comportamental. Em última instância, o modo como o homem moderno pensa e age, depende desse contexto cultural ou ideacional. Concepções-chave são geradas, como com relação à humanidade, à sociedade, à natureza, entre outras. Há, portanto, uma ética que perpassa a história da modernidade e que legitima as formas relacionais sociedade/natureza. Alguns autores foram fundamentais, mas principalmente Bacon, Hobbes e Locke.

Nesta linha de raciocínio, a questão ambiental coloca-se como uma questão de claro sentido ético, filosófico e político, afirmativa essa que permite o desvio de um caminho fácil que nos tem sido oferecido: o de que devemos nos debruçar sobre soluções práticas, técnicas, para resolver, entre outros, os graves problemas do efeito estufa, do buraco na camada de ozônio, do aquecimento global, da escassez da água, do lixo nosso de cada dia, da poluição, do desmatamento, da erosão, da pobreza econômica e cultural, logo, de uma sociedade que corre riscos. Esse caminho nos torna prisioneiros de um pensamento herdado que é, ele mesmo parte do problema a ser analisado.

Essa perspectiva da realidade é particularmente importante pois condiciona a perspectiva de que não há necessidade ética para relações que se estabelecem com máquinas. Temos, aqui, um dado fundamental: a cosmologia moderna compreende o mundo mecanicamente, portanto: torna-se desnecessária uma perspectiva ética para a relação homem/natureza. Por isso com o avanço da modernidade, a guerra (de expropriação) passa a ser de todos contra a natureza, mediada unicamente pela perspectiva hedonista e utilitarista própria da cosmovisão moderna.

Além disso, o entendimento de desfinalização cosmológica, implica no entendimento da queda da hierarquia de valores imperantes no mundo clássico e determinante por excelência da conduta do homem medieval.

O operador central, através do qual se decifra o sujeito, medida central da organização sócio-política moderna, passa a ser o egoísmo, que é a base de toda e qualquer ação. Assim, o ser humano passa a ser compreendido através dessa força egoísta de perpetuação e consecução de seus interesses. Estamos pois, diante daquilo que podemos considerar o novo 
princípio ético da modernidade: uma visão de total subordinação da natureza ao desejo (conatus) moderno humano, de cunho individualista, materialista e economicista.

Estabelecido este panorama da problemática engendrada historicamente nos campos científico, político e econômico sobre o meio ambiente, cabe agora ver como esta questão vem se colocando nos últimos anos.

Confiamos, todavia, que qualquer parecer ainda reserva as suas restrições. Portanto, reconhecemos que não temos a pretensão de apresentar uma ideia finalizada, aspiramos somente abrir um diálogo epistemológico, para poder suscitar um mal-estar. A crise gerada implica em superação, é ela que constrói o sujeito, varrendo-lhes todas as finitudes e causando nele o senso de possibilidades. As possibilidades podem ser terríveis como aprazíveis, desdobrando-se de um modo infinito de existência. Portanto, ressaltar as dificuldades, o lado obscuro das personalidades individuais que desenham o todo é uma transição essencial para a perene reinvenção do trabalho formativo com questões ambientais.

No processo histórico de percepção das consequências da ação humana sobre a natureza foram sendo utilizados conceitos que expressam diferentes graus e recortes na percepção da mesma. Por exemplo, os conceitos de ecossistema e biodiversidade. Esses conceitos, apropriados pelos movimentos em defesa do meio ambiente, foram moldando outros como o de preservação e conservação. E o de meio ambiente. Esse, inicialmente, foi concebido como modo de apreender dimensões da natureza. Todavia, o conceito de meio ambiente, reduzido exclusivamente aos seus aspectos naturais, não contempla as interdependências e interações com a sociedade, nem a contribuição das ciências sociais à compreensão e melhoria do ambiente humano.

Hoje, compreendemos meio ambiente considerando a interdependência entre o meio natural, o socioeconômico e o cultural, sob o enfoque da sustentabilidade. Isto demonstra como uma lei retrata o momento histórico em que foi elaborada e porque as leis devem ser reavaliadas de tempos em tempos.

Os movimentos e ações da sociedade em busca da conservação da natureza são, desde os seus primórdios, reação à destruição de, num primeiro momento, espécies, e a partir da concepção dos conceitos de ecossistemas e posteriormente de biodiversidade, esta preocupação e reação vai se ampliando. O modelo de desenvolvimento gerado a partir da Revolução Industrial (final do séc. XVIII) provoca aumento qualitativo e quantitativo no processo de destruição da natureza. Em paralelo, provoca a organização da sociedade em torno da conservação da natureza. 
O campo da prática é muitas vezes mais difícil de ser trilhado do que o da teoria. Mas no campo teórico a dimensão subjetiva do trabalho não pode ser desconsiderada: sem sonho ou imaginação e sem o enfretamento das dificuldades que o desejo de mudança impõe ao ser humano, mulheres e homens não transformam e não são transformados. Assim, a educação ambiental deve ser concebida em um contexto maior da educação, desvelada em seu sentido etimológico: do verbo latino educare, que significa transformar, conduzir de um lugar para outro, extraindo o que os indivíduos têm de melhor em si.

A visão ampla do mundo é um passo fundamental para uma educação transformadora, que deve ser acompanhada de uma clareza do ato educativo, uma posição política e uma competência técnica para implementar projetos a partir do aporte teórico de um profissional competente:

Desse modo, a educação deve produzir seu próprio giro copernicano, tentando formar as gerações atuais não somente para aceitar a incerteza e o futuro, mas para gerar um pensamento completo e aberto às indeterminações, às mudanças, à diversidade, à possibilidade de construir e reconstruir em um processo contínuo de novas leituras e interpretações do já pensado, configurando possibilidades de ação naquilo que ainda há por se pensar (Leff, 2000, p. 35).

A esse respeito afirmou Pedro Jacobi na 27ª ANPEd - Caxambú/2004:

A educação ambiental aponta para propostas pedagógicas centradas na conscientização, mudança de comportamento, desenvolvimento de competências, capacidade de avaliação e participação dos educandos. A relação entre meio ambiente e educação assume um papel cada vez mais desafiador demandando a emergências de novos saberes para aprender processos sociais que se complexificam e riscos ambientais que se intensificam. A ambientalização do conhecimento terá mais condições de ocorrer na medida em que se promova uma reestruturação de conteúdos, em função da dinâmica da sua própria complexidade e da complexidade ambiental, em todas as suas manifestações: sociais, econômicas, políticas e culturais (2004, p. 327).

A ambientalização educacional, nessa direção é de fundamental importância face o papel da universidade no sentido de atuar como formadora de sujeitos atuantes na construção de sociedades sustentáveis, em todos os seus campos de formação e em todos os níveis de atuação universitária. 
Desta forma, fica consignado, seguindo o estabelecido na Deliberação nำ 04/2013, de 12 de novembro de 2013 do Conselho Estadual de Educação do Paraná que no seu Artigo segundo estabelece que a Educação Ambiental deve fundamentar-se nos seguintes princípios e procedimentos orientadores da(o):

I - cuidado e conservação da comunidade de vida como sujeito de direito, ampliando e integrando o âmbito dos direitos humanos, na perspectiva da sustentabilidade;

II - Política Estadual de Educação Ambiental, de acordo com a Lei Estadual no 17.505/2013, no que tange à integração da Educação Ambiental no âmbito formal e não formal;

III - integração das políticas públicas das áreas de educação, meio ambiente, saúde, agricultura, saneamento ambiental, turismo, cultura, desenvolvimento urbano, assistência social, segurança pública entre outras;

IV - fortalecimento do papel social da escola como espaço educador sustentável, a partir de sua atuação nos territórios físicos e ambientais, como instrumento de articulação e transformação social;

V - participação e controle social das políticas públicas como mecanismos de acompanhamento e monitoramento dos resultados das ações de Educação Ambiental;

VI - articulação entre o Ensino Superior e a Educação Básica, integrando ações no âmbito do ensino, pesquisa e extensão, visando a formação inicial e continuada; VII - constituição de redes de ações socioambientais para divulgar, fortalecer e socializar práticas educativas que resultem em processos para a formação e desenvolvimento local, regional, estadual, nacional e global. (2013, p. 3)

No bojo de todo este contexto, inclui-se também como objetivo primordial da educação a questão dos Direitos Humanos, entendendo como sendo a formação para a vida e para a convivência, no exercício cotidiano dos Direitos Humanos como forma de vida e de organização social, política, econômica e cultural nos níveis regionais, nacionais e planetário. Esta compreensão é abarcada pela compreensão estabelecida sobre a educação socioambiental, que vai além, portado da simples questão ambientalista de anos passados.

Tais questões encontram-se alicerçadas no Plano Nacional de Educação em Direitos Humanos - PNEDHs e caracteriza principalmente, por ser uma política pública com dois objetivos claros: Um deles é o de construir e consolidar um projeto de sociedade pautado nos 
princípios da democracia, cidadania e justiça social e também de reforçar a construção de uma cultura de direitos humanos, que permita o princípio de uma formação de cidadania.

O PNEDH está alicerçado nos documentos internacionais e nacionais, demarcando a inserção do Estado brasileiro na história da afirmação dos direitos humanos e na Década da Educação em Direitos Humanos, prevista no Programa Mundial de Educação em Direitos Humanos e seu Plano de Ação.

Os objetivos do PNEDH são indicativos diretos à uma educação socioambiental quando apontam para:

O fortalecimento do respeito aos direitos humanos e liberdades fundamentais;

a)A promoção do pleno desenvolvimento da personalidade e dignidade humana;

b)fomento ao entendimento, a tolerância, a igualdade de gênero e a amizade entre as nações,

c) os povos indígenas e grupos raciais, nacionais, étnicos, religiosos e linguísticos;

d)estimulo à participação efetiva das pessoas em uma sociedade livre e democrática governada pelo Estado de Direito;

A construção, promoção e manutenção da paz.

Desse modo, a educação em direitos humanos é compreendida como um processo sistemático e multidimensional que orienta a formação do sujeito de direitos.

Com efeito, concebe-se a escola como um lugar privilegiado na promoção dos direitos humanos, capaz de promover como um direito em si mesmo e um meio indispensável o pleno desenvolvimento humano e as suas potencialidades, valorizando o respeito aos grupos socialmente excluídos. Essa concepção de educação busca na cidadania plena a construção de conhecimentos, o desenvolvimento de valores, atitudes e comportamentos, socioambiental e a justiça social, como princípios formadores de cidadania.

\subsection{Organização do eixo interdisciplinar}

A projeção aqui delineada de organização curricular demonstra que a FAMA estruturou os Projetos Políticos Pedagógicos de seus cursos de graduação estabelecendo o incentivo à abordagem da Educação Ambiental, a partir de uma perspectiva crítica e propositiva da inserção da Educação Ambiental na formulação, execução e avaliação das ações da instituição, para que essa como componente curricular, supere a fragmentação e compartimentalização dos saberes disciplinar. 
A organização curricular a partir do Eixo central - Ambientalização dos espaços educativos sustentáveis - inclui a questão ambiental como uma das premissas para a sustentabilidade, e por meio das dimensões que a compreende é provável delinear novos contextos de abordagem de educação ambiental, contemplando a proposta metodológica na análise e nos encaminhamentos, bem como os seus diferentes níveis e dimensões inclusas na estrutura de disciplina que compõem o eixo que permeará a matriz curricular dos cursos dessa Instituição organizado e estruturado a partir de discussões com o coletivo de professores, coordenadores de cursos, gestores resultou na proposição:

Primeiro Período: História, Cultura e Patrimônios Regionais - voltada fundamentalmente para o contexto histórico regional.

Terceiro Período: Responsabilidade sócio ambiental / tecnologias limpas;

Quarto e Quinto Períodos: Constituído, em parte, de disciplinas eletivas para cada curso voltadas à temática sócio ambiental;

Sexto Período: Seminário integrado interdisciplinar, com a alternância entre momentos teóricos e práticos;

Sétimo Período: Projetos Integradores;

Oitavo Período: Seminário de Produção Científica.

Assim, compreende-se que estamos inseridos em um parâmetro de Educação ambiental que contempla práticas integradas nas suas múltiplas e complexas relações, envolvendo aspectos de saúde, históricos, políticos, sociais, econômicos, científicos, culturais, filosóficos, estéticos, tecnológicos, psicológicos, legais e ecológicos, conforme a Lei Estadual ํo 17.505/2013, inciso I, Art. 5․ O texto da Indicação CEE/CP no 01, de 11 de novembro de 2013, que fundamentou a Deliberação CEE no 04/2013, define uma diretriz em que a

Educação Ambiental envolve o entendimento de uma educação cidadã, responsável, crítica, participativa, em que cada sujeito aprende com conhecimentos científicos e com o reconhecimento dos saberes tradicionais, possibilitando a tomada de decisões transformadoras, a partir do meio ambiente natural ou construído no qual as pessoas se integram. A Educação Ambiental avança na construção de uma cidadania responsável voltada para culturas de sustentabilidade socioambiental. (Estado do Paraná, 2013, p. 14) 
Então, a compreensão que se passa a ter de meio ambiente fica tácita, como sendo o resultado das relações de intercâmbio entre Sociedades e Natureza em espaço e tempo concretos. É consenso que o conceito de meio ambiente deve contemplar o meio social, cultural, político e não só o meio físico, logo as análises que se efetuam nos problemas ambientais devem considerar as inter-relações entre o meio natural, seus componentes biológicos, sociais e também os fatores culturais. Consequentemente, os problemas ambientais não são unicamente os que derivam do aproveitamento dos recursos naturais e os que se originam da contaminação, mas também aqueles advindos do subdesenvolvimento.

Cada vez que se pretenda caracterizar uma realidade ambiental, esta deverá ser considerada dentro de um marco espacial e temporal concreto. Uma realidade ambiental não aparece como produto exclusivo das leis naturais, pelo contrário, é o resultado do processo histórico-cultural das relações entre sociedades e natureza.

A ambientalização da educação passa então a entender que o Currículo entendido etimológico como correr, curso, recorrido, caminho (atalho), implica o conceito de processo, e então passa a englobar programas, planos, cursos, enfim, um conjunto organizado de experiências de aprendizagem. Com isso estamos passando do estágio programático para uma concepção mais ampla de experiências formativas visando novos estilos de desenvolvimento, englobando uma postura institucional consubstanciada em novos elementos básicos que compõem o currículo, gestão institucional, processo de ensino e aprendizagem e experiências dos alunos, a partir da Ambientalização dos espaços educativos sustentáveis.

O propósito de integrar diferentes ramos do conhecimento científico e técnico em torno de um objetivo comum é anterior à demanda de produção de um saber interdisciplinar que propõe a problemática ambiental do desenvolvimento. E para tal a interdisciplinaridade é proclamada não só como um método e prática para a produção de conhecimentos e para sua integração operativa na explicação e resolução dos cada vez mais complexos problemas do desenvolvimento, mas surge com a pretensão de promover intercâmbios teóricos entre as ciências e de fundar novos objetos científicos.

Para Leff (2000, p.72) o "ambiental aparece como um campo de problematização do conhecimento que induz um processo desigual de internalização de certos princípios, valores e saberes ambientais dentro dos paradigmas tradicionais das ciências". Esse processo tende a gerar especialidades, métodos e planejar o processo de desenvolvimento econômico sobre bases ambientais. 


\subsection{Desafios das questões ambientais no meio pedagógico}

Percorremos até aqui um caminho que nos permitiu problematizar o papel do ensino superior na formação de profissionais e debater as questões envolvidas na inserção da educação ambiental com vistas a uma forma voltada à sustentabilidade.

A proposição em análise intenciona desempenhar o papel de inquietude para gerar um debate sobre a criatividade na organização curricular como forma de trazer novos elementos epistemológicos para compor a práxis pedagógica a partir de questões ambientais, buscando inscrever na contemplação do meio questionamento que gere a sua atualização e sua recriação. Isso não implica dizer que a Educação Ambiental apresenta somente dificuldades, mas também significa reconhecer os seus limites. Ela necessita de uma análise mais crítica, extraindo os momentos fecundos e compreendendo as tensões presentes em suas práticas e discursos.

Debater os desafios das questões ambientais no meio pedagógico inscreve-se na avaliação de uma trajetória que tem reflexos de diferentes ordens. Ao arriscar uma avaliação da Educação Ambiental, entretanto, adentramo-nos num campo minado de incertezas e subjetividade múltipla. Mas não temos a pretensão de dar receitas de superação, nem temos em vista suprimir as diferenças para que a realidade seja mais palatável. Quer-se apenas apontar alguns obstáculos, que discutidos epistemologicamente, podem auxiliar nas trajetórias delineadas pela Instituição. Assim, entende-se que ambientalizar o currículo, significa instaurar, no sistema educativo, uma cadeia de mudanças que abranjam:

inovações conceituais, metodológicas e atitudinais, mas também estruturais e organizacionais, que permitam um enfoque interdisciplinar no currículo, que facilite um planejamento global de objetivos e conteúdos, que se aproxime da compreensão da complexidade e da visão planetária (...) que facilitem a descentralização e a flexibilidade do currículo necessárias para adaptar-se ao entorno e dar respostas as suas inquietudes. (Gonzáles Muñoz, 1996, p. 37)

Esse processo consecutivo de ambientalização poderá propiciar à comunidade acadêmica, vivências não só de práticas, mas também de princípios, de atitudes e valores da sustentabilidade, que sejam incorporados pela comunidade que vive além dos seus muros.

Justifica-se a relevância de investigar se, ao incorporar questões relativas à temática ambiental, as características de um estudo ambientalizado, tais como as concebidas na 
literatura estão presentes no currículo dos seus cursos, e mais, se essa incorporação tem se materializado em práticas e ações concretas no cotidiano da universidade.

Os documentos analisados que tratam dos planos de ensino, projetos de pesquisa, das ações e das práticas pedagógicas cientificam a existência de uma preocupação da instituição de ensino superior, enquanto instituição pública em realizar o processo de ambientalização e a inserção da sustentabilidade na comunidade universitária e no seu entorno.

\section{Considerações finais}

Completando essa etapa de trabalho e análise retomando o objetivo de sugerir subsídios e estratégias para organização curricular de cursos de graduação, entende-se que é necessário instituir uma cultura ambiental na universidade, que possa discutir de forma ampla com a comunidade universitária uma política que sugira e introduza modificações no que se refere a metodologias e abordagens para ambientalizar as práticas nos currículos dos cursos de graduação, de forma articulada com a pesquisa, extensão e ensino, para que a instituição possa se adequar as Políticas Públicas tornando-se assim, de fato uma menção no campo da sustentabilidade e responsabilidade socioambiental.

A ambientalização e a concepção de uma política institucional de cunho ambiental devem ser claramente compreendidas como não restrita a gestão institucional, mas também o são dos docentes e pesquisadores e, sobretudo que são partes da comunidade acadêmica que possuem, por definição, uma visão global da organização curricular, e aos quais incumbe tomar decisões com impacto em toda a instituição. E cônscios que do processo de constituição e transição para uma racionalidade ambiental implica processos políticos e sociais que transcendem à confrontação de duas lógicas opostas, que mobilizam e obstaculizam as mudanças históricas para construir esta nova racionalidade socioambiental.

O caminho, aqui explicitado, conclui a demarcação de um movimento tensivo entre polos distintos. Ter a audácia de mostrar as dificuldades de trabalhar com o tema meio ambiente e as dimensões e sustentabilidade, ao invés de considerá-la como a única opção possível, é também circunscrevê-la em um caminho aberto relacionado com o caráter entrelaçado do ser humano com a natureza. Caráter este imprevisível e dramático, porque se trata de um processo que emerge no intento da busca de caminhos.

Por fim, vale estabelecer alguns encaminhamentos que possibilitarão nortear os trabalhos docentes no início desta caminhada na Faculdade Municipal de Educação e Meio Ambiente: 


\section{a) Anteceder as discussões específicas das várias disciplinas por reflexões sobre a} questão ambiental e sobre a Educação Ambiental

O debate sobre a temática ambiental em geral deve possibilitar perceber os diferentes posicionamentos sobre estas questões. Assim, os acadêmicos devem ser levados a uma tomada de posição em debates, tais como a presença/ausência do ser humano no mundo natural, o ambiente natural e o ambiente construído, a natureza intocada e a natureza transformada pela ação humana, o antropocentrismo e o ecocentrismo, o papel da ciência e tecnologia e os modelos econômicos subjacentes às propostas de gestão ambiental. Entendemos que é sempre fundamental, em qualquer intervenção de Educação Ambiental, abordar estas questões mais amplas, pois do contrário os debates sobre temas específicos (resíduos, água, poluições etc.) correm o risco de tornar-se descontextualizados de um debate mais amplo sobre a relação entre desenvolvimento econômico e ambientalismo, isolando a temática ambiental de suas relações sociais, políticas e econômicas.

b) Propor um trabalho prático de ensino ou pesquisa ao longo de todo o semestre

Esta opção pauta-se pela orientação de que é fundamental aliar teoria e prática na formação inicial dos profissionais, para evitar a enorme lacuna entre estes dois polos. Boa parte dos cursos das universidades brasileiras ainda não resolveu esta questão na formação acadêmica, mantendo a divisão entre formação específica nos primeiros anos e formação prática escassa no curso.

c) Ensinar, sempre que possível, de modo indissociável, sobre os temas da questão ambiental, da Educação Ambiental e os conteúdos da disciplina

O desafio de ensinar sobre temas distintos simultaneamente, exige ensinar empregando procedimentos e atividades didáticas mais participativas e inovadoras. Assim, deve-se buscar em cada aula, introduzir procedimentos e, sempre que possível, propor a discussão sobre a viabilidade de seu emprego no contexto social. Para isto será preciso recorrer a diferentes tipos de procedimentos e atividades didáticas: discussões; aulas expositivas participativas; desenvolvimento de trabalho de intervenção ou pesquisa; trabalho de campo; análise de materiais didáticos, entre outros. 


\section{d) Coligação de disciplinas}

Estabelecer uma disciplina colegiada - na formação inicial - "para fugir dos moldes das disciplinas tradicionais do currículo", numa perspectiva interdisciplinar, através da elaboração de projeto de ensino com objetivos comuns, trabalhado por docentes de diferentes áreas sob diferentes ângulos de análise - oferecido, simultaneamente, para cursos de diferentes campos do saber. Os encontros e eventos, promovidos por esse campo, se constituem espaço/tempos de um movimento de institucionalização de formação em Educação Ambiental.

\section{e) Núcleo de Estudos Integradores}

O Núcleo de Estudos Integradores, que pode ser criado em todos os cursos, visa o "enriquecimento curricular" que também pode se constituir num espaço propício ao desenvolvimento de atividades/ações nterdisciplinares de Educação Ambiental, ao promover "atividades práticas, seminários, iniciação científica, monitoria e extensão, dentre outras vivências que assegurem aprofundamentos e diversificação de estudos, experiências e utilização de recursos pedagógicos.

A trajetória traçada pelo Eixo - Ambientalização dos espaços educativos sustentáveis deve mirar adiante, desafiar, constituir um horizonte de referência, continuamente palpitante, e que pelo próprio caminhar, se move à frente, abrindo dimensões ainda não vistas, ampliando horizontes e emprestando significação ao próprio andar. Assim, debater nossos desafios pode também significar nossa caminhada, talvez de avanços e também de recuos, para as descobertas e o olhar crítico necessário a qualquer pensamento.

E ter em consenso com os articuladores da proposta que a ambientalização no ensino superior não se reduz ao âmbito interno das mudanças curriculares e ou mudanças na gestão institucional, mas requer um redimensionar das pesquisas, das práticas de extensão e nas práticas pedagógicas e de ensino na sua ligação com a comunidade local e regional.

\section{Referências}

Brasil. (1999). Lei no 9.795, de 27 de abril de 1999. Dispõe sobre a educação ambiental, institui a Política Nacional de Educação Ambiental e dá outras providências. Diário Oficial da União, Brasília, DF. Disponível em http://www.planalto.gov.br/ccivil 03/leis/L9795.htm

Comitê Nacional de Educação em Direitos Humanos. (2006). Plano Nacional de Educação em Direitos Humanos. Brasília: Secretaria Especial dos Direitos Humanos, Ministério da Educação, Ministério da Justiça, Unesco.

Carvalho, Isabel Cristina de Moura. (2004). Educação Ambiental Crítica: nomes e endereçamentos da educação. In Layrargues, Philippe Pomier (Coord.) Identidades da educação ambiental brasileira/. (pp. 13-24). Brasília: Ediciões MMA. 
Estado do Paraná. (2013). Deliberação no 04/2013. Conselho Estadual de Educação: Curitiba. Disponível em http://www.cee.pr.gov.br/arquivos/File/pdf/Deliberacoes/2013/deliberacao 04 13.pdf

Estado do Paraná. (2013). Indicação no 01/2013. Conselho Estadual de Educação: Curitiba. Disponível http://www.cee.pr.gov.br/arquivos/File/pdf/Deliberacoes/2013/deliberacao 01 13.pdf

Estado do Paraná. (2013). Lei Estadual no 17.505/2013 - Institui a Política Estadual de Educação Ambiental e o Sistema de Educação Ambiental e adota outras providências. Disponível em http://www.legislacao.pr.gov.br/legislacao/pesquisarAto.do?action=exibir\&codAto=85172

Estado do Paraná. (2015). Deliberação № 02/2015-CEE/PR. Dispõe sobre as Normas Estaduais para a Educação em Direitos Humanos no Sistema Estadual de Ensino do Paraná Disponível em http://pitangui.uepg.br/secrei/Legisllnicial\%20Arquivos/Deliberacao\%20CEE\%20PR\%2002 \%20\%202015.pdf

Gonzáles Muñoz, Maria C. (1996). Principales tendencias y modelos de la educación ambiental en el sistema escolar. Revista ibero-americana de educación, 11, 13-74.

Jacobi, Pedro e Luzzi, Angel, Daniel. (Noviembre de 2004). Educação e meio ambiente - um diálogo em ação, (p. 327). In Anais do $27^{\circ}$ Encontro Anual da Associação Nacional de Pós-Graduação e Pesquisa em Educação - Anped, Caxambu, Rio de Janeiro.

Jacobi, Pedro. (2005). Educação Ambiental: o desafio da construção de um pensamento crítico, complexo e reflexivo. Educação e Pesquisa. São Paulo, 31(2), 233 - 250.

Leff, Enrique. (2000). Pensar la complejidad ambiental. In: Leff, E. La complejidad ambiental, (pp. 7- 35). México: Siglo XXI.

Leite Lopes, José Sérgio. (2006). Sobre processos de ambientalização dos conflitos e sobre dilemas da participação. Horizontes antropológicos, Porto Alegre, 12 (25), 31- 64.

Ministério da Educação do Brasil. (2012). Resolução no 2, de 15 de junho de 2012. Estabelece as Diretrizes Curriculares Nacionais para a Educação Ambiental. Ministério da Educação Conselho Nacional De Educação Conselho Pleno. Disponível em http://portal.mec.gov.br/index.php?option=com docman\&view=download\&alias=10988rcp002-12-pdf\&category slug=maio-2012-pdf\&ltemid=30192

Morin, Edgar; Kern, Anne Brigitte. (1993). Terre Patrie. Paris: Seuil.

Moraes, Maria Cândida. (2004). Educação, aprendizagem e cidadania no século XXI. Petropólis, RJ: Vozes.

Nicolescu, Basarab. (2000). Educação e transdisciplinaridade. Brasilia: Unesco.

Trajber, Rachel e Sato, Michèle. (2010). Escolas sustentáveis: incubadoras de transformações nas comunidades. Revista Eletrônica Mestrado Educação Ambiental, V. especial, 70 78. 